\title{
The European School Fruit Scheme: impact on children's fruit and vegetable consumption in North Rhine-Westphalia, Germany
}

\author{
Sarah Methner, Gesa Maschkowski and Monika Hartmann* \\ University of Bonn, Institute for Food and Resource Economics, Chair of Agricultural and Food Market Research, \\ Nußallee 21, 53115 Bonn, Germany
}

Submitted 7 April 2016: Final revision received 11 August 2016: Accepted 19 August 2016: First published online 3 0ctober 2016

\begin{abstract}
Objective: To assess the impact of the European School Fruit Scheme (SFS) in North Rhine-Westphalia, Germany, on children's fruit and vegetable (F\&V) consumption, in particular frequency.

Design: The study consisted of a pre-test/post-test design with an intervention (eight primary schools) and a control group (two primary schools). Children's F\&V consumption frequency was measured prior to the introduction of the SFS in 2010 and after one year's delivery of F\&V (2011).

Setting: Ten primary schools in North Rhine-Westphalia, Germany.

Subjects: In total, 499 primary-school children aged 6-11 years, 390 in the intervention and 109 in the control schools.

Results: Children highly appreciated the SFS. More than $90 \%$ evaluated the programme positively. Children in the intervention group showed a significant increase in $\mathrm{F} \& \mathrm{~V}$ intake frequency from baseline to follow-up, from on average $1.26(\mathrm{sD} 1.37)$ to $2.02(\mathrm{SD} 1.33)$ times/d $(P=0.000)$. The intervention variable had a highly significant impact on children's F\&V consumption frequency, even after controlling for gender, age and stay at school for lunch $(\beta=0.773 ; 95 \%$ CI 0.59 , 0.96). The SFS did not induce a reduction of F\&V consumption at home. In the control group a non-significant decline in F\&V consumption frequency from 1.31 (SD 1.26$)$ to 1.18 (SD 1.34) times/d $(P=0.325)$ was observed.

Conclusion: One year after the programme's implementation, the SFS led to a significant short-term increase in children's F\&V consumption.
\end{abstract}

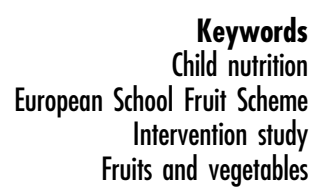

There is ample scientific evidence that the dietary patterns of children and adolescents have a significant influence on their immediate and long-term health and well-being ${ }^{(1-3)}$. A diet rich in fruits and vegetables $(\mathrm{F} \& \mathrm{~V})$ is recognized to be a cornerstone in lowering the risk of chronic diseases such as CVD or cancer ${ }^{(4-7)}$. Despite these health benefits, consumption of F\&V by children falls well below the recommended daily amounts ${ }^{(8-10)}$. In Germany, a study by the Robert Koch-Institute ${ }^{(11)}$ revealed that only $7 \%$ of 6-11-year-old girls and only 6\% of 6-11-year-old boys reach the daily recommendation for vegetables ${ }^{(12)}$ and only 19 and $15 \%$, respectively, reach the daily recommendation for fruits ${ }^{(11)}$. The results are similar for other countries $^{(9)}$.

The framework of the Social Cognitive Theory, as one of the contemporary theories to understand human nutritional behaviour, is often used in the development and analysis of nutritional intervention studies ${ }^{(13-17)}$. According to this theory, nutritional behaviour is a complex construct ${ }^{(15,16,18)}$ with multiple factors such as personal (gender, age or migration background), behavioural (involvement in food preparation) and environmental (availability of or accessibility to F\&V) factors and interdependencies among these ${ }^{(13-16,18,19)}$. Nutrition-oriented interventions in school settings can address environmental as well as behavioural factors and thus are considered potentially valuable for promoting children's health ${ }^{(20)}$.

Indeed, studies evaluating F\&V interventions in schools reveal that such schemes can be a very effective mechanism for improving F\&V consumption by children ${ }^{(21-24)}$. Since interventions in schools allow to address the demographically widest sample of the target population, reaching children of most socio-economic backgrounds, they can play a central role in promoting a diet rich in $\mathrm{F} \& \mathrm{~V}$, inducing improvements also among disadvantaged socio-economic groups $^{(25-27)}$.

Thus, to promote consumption of F\&V among European school-aged children, EU Agriculture Ministers agreed in November 2008 to introduce the School Fruit Scheme (SFS) ${ }^{(28)}$.

In North Rhine-Westphalia (NRW; the largest federal state of Germany), the SFS was initiated in March 2010. 
It started in 355 schools consisting of 289 elementary and sixty-six special-needs schools. Every pupil received $100 \mathrm{~g}$ $\mathrm{F} \& \mathrm{~V}$ each day, financed by the EU and the federal state. Generally, F\&V were served in the participating schools as a snack during morning break. However, whether F\&V were prepared by pupils, parents, teachers or kitchen staff varied from school to school.

The objective of the current paper was to analyse if the SFS in NRW was able to increase children's F\&V intake frequency after the ending of a one-year, free-of-charge intervention of daily $\mathrm{F} \& \mathrm{~V}$ provision.

\section{Methods}

\section{Study design and sample}

To analyse whether the SFS in NRW had been successful in increasing schoolchildren's F\&V intake, a pre-test/posttest design was used with an intervention group (eight primary schools) and a control group (two primary schools). The impact of the SFS was assessed at baseline (prior to intervention) in spring 2010 and one year after the implementation of the intervention in spring 2011 (follow-up). Ten elementary schools were selected for the study: eight of the 355 schools taking part in the SFS in NRW (intervention group) and two elementary schools in NRW that did not want to participate in the scheme (control group). To secure a high heterogeneity among schools, the sample included schools with a high and low level of social deprivation and schools with a high and low degree of nutrition education. Social deprivation was classified (high/low) according to criteria set by the Ministry for Climate Protection, Environment, Agriculture, Conservation and Consumer Protection (MKULNV) of NRW, combined with assessments of the headmasters regarding the level of social deprivation of their students. Degree of nutrition education was grouped (high/low) based on the participating schools' nutrition education concepts. The study had a quasi-experimental design as schools had to apply for the SFS and had to be selected by the MKULNV of NRW to become part of the SFS, making it impossible for the researchers to randomly assign schools to experimental and control groups.

\section{Instruments}

Surveys were conducted with children, parents, teachers and headmasters to gain comprehensive information with regard to the perception, organization and success of the SFS. The present paper focuses primarily on the findings obtained from the children's survey.

Children had to fill in a $24 \mathrm{~h}$ dietary recall as a whole class exercise. Two versions of the questionnaires were developed, one for children staying at school for lunch and the other for those going home for lunch. The $24 \mathrm{~h}$ dietary recall used in the present study was originally developed within the scope of the 'Grab 5 Project' in the UK and has been adjusted to German conditions. The questionnaire's critical aspects of validity, statistical reliability and sensitivity to change were tested in a 3-year study in the $\mathrm{UK}^{(29)}$. A pre-test of the adapted German version of the questionnaire was conducted in two elementary-school classes. Only questionnaires of children with completed baseline and follow-up $24 \mathrm{~h}$ dietary recalls and those revealing reasonable data (e.g. F\&V consumption frequency less than 7 times/d) were considered in the analysis. The $24 \mathrm{~h}$ recall allowed $\mathrm{F} \& \mathrm{~V}$ consumption frequencies to be traced to different times of day. In addition, children were asked about their age, gender and migration background (no, one parent or two parents). Moreover, in 2011 , children in the intervention group were requested to evaluate the SFS on a 5 -point smiley scale ('very good' $=5$ to 'very bad' $=1$ ). The parents' social status was identified by means of a written survey addressed to parents including questions on their educational level and employment status. This information served to calculate the 'Brandenburger Sozialindex'(30). The study and data handling were approved by the Ministry of Education and the MKULNV of NRW as well as by the data protection officer of the University of Bonn. Anonymized number codes allowed to link baseline data to follow-up data for each individual.

\section{Statistical analysis}

The impact of the intervention was measured by changes in $\mathrm{F} \& \mathrm{~V}$ consumption frequencies. Potatoes, F\&V juices and most of the composite foods were excluded from the analysis. Based on a quantitative content analysis ${ }^{(31)}$ the $\mathrm{F} \& \mathrm{~V}$ intake frequency per day was counted. Two students, both with approximately $20 \mathrm{~h}$ of formal training, conducted the coding of the $24 \mathrm{~h}$ food recalls provided by the children. Intercoder reliability was assessed by Holsti's method $^{(32)}$ with an overall agreement between coders of $0 \cdot 98^{(31)}$. Differences between the intervention and control groups at baseline concerning age, gender, migration background, parents' social status and children's stay at school for lunch (yes/no) were explored using the $\chi^{2}$ test and Student's $t$ test. The Mann-Whitney $U$ test for nonparametric data was applied to compare F\&V consumption frequency of the intervention and control groups at baseline. To analyse the changes in F\&V consumption frequency between baseline and follow-up, the nonparametric Wilcoxon test for paired samples was used. Moreover, to account for the clustered data structure (time, children and classes), hierarchical linear modelling was implemented using the framework provided by Raudenbush and $\mathrm{Bryk}^{(33)}$.

First, a three-level model without structural covariates was estimated dividing the total variance in children's F\&V consumption frequency into three components, namely time, children and class. A fourth level for the component, 
school, would have been desirable to consider. However, this was not possible given the small number of schools (ten schools) in our sample. In order to estimate the effect of explanatory factors on children's F\&V consumption frequency, children and class characteristics were included in the unconditional model. The explanatory variables of intervention status, gender, stay at school for lunch (dummies) and age were included (fixed effects) additionally. The variable age was coded as grand mean centred to simplify model interpretation and to reduce estimation errors $^{(34,35)}$. Statistical analyses were performed with the statistical software package IBM SPSS Statistics Version 20.0, while MLwiN 2.26 (University of Bristol, Bristol, UK) was used for the multilevel modelling approach. Type 1 error rate was set at an $\alpha$ level of $P<0.05$.

\section{Results}

\section{Sample characteristics}

At baseline in 2010, 587 second and third graders completed the questionnaire; of those, 512 also took part in the follow-up survey in 2011 (as third and fourth graders). Exclusion of children who were ill the day before data collection and of children with inconsistent data resulted in 499 children for whom baseline and follow-up data were available (390 in the intervention and 109 in the control group). In the intervention group the mean age was 8.35 (SD 0.80) years, while children in the control group were slightly older ( 8.67 (sD 0.78 ) years; $P=0.000$ ). In the latter group a smaller proportion of children stayed at school for lunch compared with the intervention group (27.7 v. 36.4\%; $P=0.037)$. No difference existed regarding gender $(P=0.558)$, migration background $(P=0.309)$ and parents' social status $(P=0 \cdot 435)$ between the control and intervention groups.

\section{Children's evaluation of the School Fruit Scheme}

Children highly appreciated the SFS. More than $90 \%$ evaluated the programme positively $(70 \%$ gave the highest and $20 \%$ gave the second highest score on a 5-point smiley scale from 'very positive' $(=5)$ to 'very negative' $(=1)$ ). Seventy-eight per cent of the children responded to the request to state what they liked about the programme (open question). The taste and the opportunity to eat their favourite F\&V were mentioned most often. In addition, $31 \%$ of the children provided information on what they did not like (open question). Lack of taste of some of the F\&V served in the framework of the SFS was stated most frequently.

\section{Effect of the School Fruit Scheme on fruit and vegetable consumption frequency}

The intervention and control groups were comparable regarding the frequency of their $\mathrm{F} \& \mathrm{~V}$ consumption per day at baseline (see Table 1). As expected, F\&V consumption in the baseline study was low. The $24 \mathrm{~h}$ recall revealed that $36.9 \%$ of the children in the intervention group and $32.1 \%$ of the children in the control group did not eat any F\&V the day before data collection. Of those who indicated that they had eaten $F \& V$ the previous day, the consumption frequency 'once a day' was most often mentioned (29.0\% in the intervention group and $32 \cdot 1 \%$ in the control group).

Compared with baseline, average $F \& V$ consumption frequency per day increased significantly in the intervention group in 2011, whereas there was a non-significant decline in F\&V consumption frequency per day in the control group (see Table 1). In line with this development, a significant difference existed in total frequency of F\&V consumption in the follow-up study between the intervention and the control groups (see Table 1). In the intervention group both genders increased their $\mathrm{F} \& \mathrm{~V}$ consumption frequency $(P=0 \cdot 000)$. Nevertheless, girls ate F\&V more often than boys did. This was true for both the baseline (1.50 (SD 1.46) v. 1.01 (SD 1.22) times/d) and the follow-up study (2.32 (sD 1.31) v. 1.70 (SD 1.28) times/d, respectively; both $P=0 \cdot 000)$.

Figure 1 provides information on the proportion of children with F\&V consumption frequency of $0,1,2,3$ or $\geq 4$ times/d at baseline and follow-up for the intervention group. It demonstrates that the proportion of children with

Table 1 Consumption frequency of fruits and vegetables (F\&V; times/d) in 2010 and 2011, as well as respective changes ${ }^{(47)}$, in the intervention and control groups of primary-school children aged 6-11 years, North Rhine-Westphalia, Germany

\begin{tabular}{|c|c|c|c|c|c|c|c|}
\hline & \multicolumn{3}{|c|}{ Intervention group ( $n$ 390) } & \multicolumn{3}{|c|}{ Control group (n 109) } & \multirow[b]{2}{*}{ Significance } \\
\hline & Mean & SD & Median & Mean & SD & Median & \\
\hline \multicolumn{8}{|c|}{ Intervention $v$. control group } \\
\hline 2010 & $1 \cdot 26$ & 1.37 & 1.00 & 1.31 & 1.26 & 1.00 & $P=0.458^{*}$ \\
\hline 2011 & 2.02 & 1.33 & 2.00 & $1 \cdot 18$ & 1.34 & 1.00 & $P=0.000^{\star}$ \\
\hline Change (2011-2010) & +0.76 & 1.66 & 1.00 & -0.13 & 1.39 & 0.00 & $P=0.000^{\star}$ \\
\hline \multirow{2}{*}{2010 v. 2011} & 1.26 to 2.02 & & & & & & $P=0.000 \dagger$ \\
\hline & & & & 1.31 to 1.18 & & & $P=0.325 \dagger$ \\
\hline
\end{tabular}

*Mann-Whitney $U$ test for two independent samples.

†Wilcoxon test for two dependent samples: 2010 v. 2011. 
no F\&V consumption in the intervention group declined considerably from 36.9 to $9.5 \%$, whereas the proportions of children with consumption frequencies of 1 time/d or above increased considerably. The situation proved quite different for the control group. In this group the proportion of children not consuming $\mathrm{F} \& \mathrm{~V}$ even increased slightly (from $32 \cdot 1$ to $37 \cdot 6 \%$; data not shown).

Providing children with $\mathrm{F} \& \mathrm{~V}$ at school might lead to a reduction in consumption during the rest of the day. Thus it is interesting to consider the change in consumption by time of the day at baseline and follow-up for the intervention and control groups. The results showed that the intervention group had significantly increased their $\mathrm{F} \& \mathrm{~V}$ consumption frequency before midday from $0 \cdot 17$ times/d at baseline in 2010 to 0.97 times/d $(P=0.000)$ at follow-up in 2011. This increase was not compensated by a significant reduction in consumption over the rest of the day (data not shown). Moreover, in 2011, the intervention group ate $\mathrm{F} \& \mathrm{~V}$ before midday significantly more often than the control group (0.97 v. 0.23 times/d; $P=0 \cdot 000)$. In the control group, no significant differences

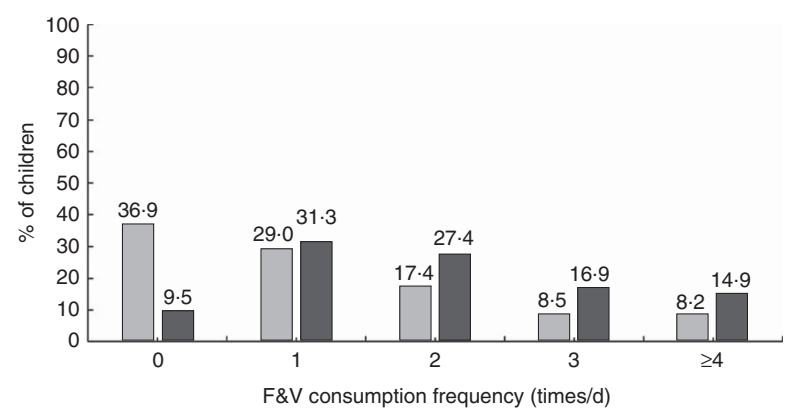

Fig. 1 Proportions reporting different consumption frequencies of fruits and vegetables (F\&V) per day in $2010(\square)$ and $2011(\square)$ in the intervention group ( $n$ 390) of primary-school children aged 6-11 years, North Rhine-Westphalia, Germany in $F \& V$ consumption frequency could be detected for any time of the day between baseline and follow-up (data not shown).

The results of the hierarchical linear modelling are summarized in Table 2 . Table 2 indicates that in the unconditional three-level model (Model 0), 6.3\% of the variance in children's F\&V consumption frequency per day can be attributed to the class level, $16.9 \%$ to the child level and $77 \cdot 3 \%$ to the time level (two measurements: 2010 and 2011). The inclusion of the intervention variable had a highly significant impact on children's F\&V consumption frequency per day $(\beta=0.763 ; 95 \%$ CI $0.58,0.95)$ and led to an improvement of the model as measured by a comparison of the likelihood ratio test of Model 1 and Model 0. Even after controlling for gender, age and stay at school for lunch, the intervention variable remained highly significant $(\beta=0.773$; $95 \%$ CI $0.59,0.96$ ). Due to a large number of missing values for the variables parents' social status and migration background, and only little influence on the results from leaving out these variables, we conducted model estimation without these variables. Gender proved to be the only significant control variable. The results indicated that girls ate F\&V more often than boys did.

\section{Discussion}

Our results provide evidence that the SFS as implemented in NRW in 2010 led to a significant increase in children's F\&V consumption after one year of participation.

To our knowledge, documentation of the impact of the SFS in Germany is still limited to evaluation reports prepared for the respective funding organizations. As they do not include any econometric modelling, they are not able to identify the main factors influencing the impact of the SFS on children's F\&V consumption. Thus the present

Table 2 Hierarchical linear model to estimate the intervention effect ${ }^{(47)}$ of the European School Fruit Scheme in North Rhine-Westphalia, Germany, on the fruit and vegetable consumption of primary-school children aged 6-11 years

\begin{tabular}{|c|c|c|c|c|c|c|}
\hline & \multicolumn{2}{|c|}{ Model 0} & \multicolumn{2}{|c|}{ Model 1} & \multicolumn{2}{|c|}{ Model 2} \\
\hline & $\beta$ & $95 \% \mathrm{Cl}$ & $\beta$ & $95 \% \mathrm{Cl}$ & $\beta$ & $95 \% \mathrm{Cl}$ \\
\hline \multicolumn{7}{|l|}{ Fixed part } \\
\hline Constant & 1.558 & $1.41,1.70$ & 1.275 & $1 \cdot 10,1.46$ & 0.982 & $1.17,0.80$ \\
\hline Intervention (yes) & - & - & 0.763 & $0.58,0.95$ & 0.773 & $0.59,0.96$ \\
\hline Gender (female) & - & - & - & - & 0.495 & $0.31,0.68$ \\
\hline Age (grand mean centred) & - & - & - & - & -0.013 & $-0.12,0.10$ \\
\hline At school for lunch (yes) & - & - & - & - & 0.055 & $-0.16,0.27$ \\
\hline \multicolumn{7}{|l|}{ Random part } \\
\hline $\begin{array}{l}\text { Time level (Level 1; variance within children) }{ }^{\star} \\
\%\end{array}$ & \multicolumn{2}{|c|}{$\begin{array}{c}1.499 \\
77.3\end{array}$} & \multicolumn{2}{|c|}{1.276} & \multicolumn{2}{|c|}{1.276} \\
\hline $\begin{array}{l}\text { Child level (Level 2; variance between children)† } \\
\%\end{array}$ & \multicolumn{2}{|c|}{$\begin{array}{l}0.327 \\
16.9\end{array}$} & \multicolumn{2}{|c|}{0.437} & \multicolumn{2}{|c|}{0.382} \\
\hline $\begin{array}{l}\text { Class level (Level 3; variance between classes) } \ddagger \\
\%\end{array}$ & \multicolumn{2}{|c|}{$\begin{array}{c}0.112 \\
6.3\end{array}$} & \multicolumn{2}{|c|}{0.083} & \multicolumn{2}{|c|}{0.082} \\
\hline$-2 \times \log$ likelihood & \multicolumn{2}{|c|}{3446.572} & \multicolumn{2}{|c|}{3359.429} & \multicolumn{2}{|c|}{$3330 \cdot 694$} \\
\hline
\end{tabular}

${ }^{*} n_{\text {time }} 998$.

$\dagger n_{\text {children }} 499$

$\ddagger n_{\text {classes }} 34$. 
study is the first one for Germany to obtain statistical insights from application of econometric methods.

On average, children in the intervention group showed an increase in F\&V consumption frequency of 0.76 times/d between baseline and follow-up, while there was a slight, although insignificant, decline in $\mathrm{F} \& \mathrm{~V}$ consumption frequency in the control group. The literature review by Knai et al. covering a broad scope of interventions aimed at promoting $\mathrm{F} \& \mathrm{~V}$ consumption of children in different countries described positive changes in F\&V consumption of between 0.30 and 0.99 servings/ $\mathrm{d}^{(24)}$. Although we measured consumption in frequencies per day and not in servings per day, our results can be considered comparable to the ones summarized in Knai et al. ${ }^{(24)}$. The same holds true if compared with the results of the review articles of school-based interventions by de Sa and Lock $^{(23)}$, French and Stables ${ }^{(36)}$ as well as Evans et al. ${ }^{(21)}$.

The present study was based on almost the same $24 \mathrm{~h}$ dietary recall questionnaire developed and validated by Edmunds and Ziebland ${ }^{(29)}$ and used in the 'Grab 5 Project' evaluation by Edmunds and Jones ${ }^{(37)}$. The 'Grab 5 Project' aimed at encouraging children to eat more F\&V by information, education and activities such as fruit tuck shops. The authors detected a slightly lower consumption increase per child of 0.5 times/d compared with the present study ${ }^{(37)}$. The study by Bere et al. is similar to the present one in that the authors analysed the effects of providing children with free fruit or vegetables every school day. Their results are in the same range as in the present study: children increased their F\&V consumption to 0.9 servings/ $\mathrm{d}^{(38)}$. Only few studies so far have investigated the longer-term effect of school-based intervention schemes, indicating only moderate or no lasting effects ${ }^{(39,40)}$.

Analysis of gender differences in F\&V intake indicated that girls eat $F \& V$ more often than boys. These results are similar to those described in other studies ${ }^{(8,9,39,40)}$ and can be explained by girls' greater liking for $F \& V^{(41-43)}$ and boys' lower appreciation of F\&V availability ${ }^{(38)}$ and in general lower motivation to consume $F \& V^{(44,45)}$. In 2011, after one year of SFS, an intervention effect could be detected in both genders. However, in 2011 girls still ate F\&V more often than boys.

Overall, the present analysis showed that the SFS in NRW led to an increase in F\&V consumption frequency among primary-school pupils. By assessing food consumption patterns for particular times of day in our data, it became evident that children in the intervention group ate F\&V more frequently before midday at follow-up than did children in the control group at follow-up, or than did the intervention children at baseline; thus suggesting an effect of the F\&V provision. Moreover, there was no significant decline in the F\&V consumption frequency at other times of day. Thus, we saw no substitution effect.

The study has several limitations. Due to the small sample size and the non-randomization, generalizability is confined. The consideration of primary-school children's cognitive ability limits the choice of suitable instruments to measure consumption. We used a $24 \mathrm{~h}$ recall, thus measuring consumption on the previous day that could have deviated from the usual consumption pattern of the respective child. However, the questionnaire used was specifically developed for this age group ${ }^{(29)}$ and has the advantage of being sensitive to even small changes in consumption patterns ${ }^{(29,46)}$. An analysis of children's food consumption over more than one day based on several $24 \mathrm{~h}$ recalls would have been desirable, but was beyond the scope of the present study. Another limitation is that there was no possibility to test for a long-term intervention effect (post-intervention run-out).

\section{Conclusions}

The current study provides evidence for the effectiveness of the SFS in NRW. Our results show that the scheme has been successful in increasing children's consumption frequency of $F \& V$ per day, after one year of intervention. The results also show that the regular provision of $F \& V$ is highly appreciated by the children. Future studies should include larger samples, measure children's consumption over more than one day, and investigate the longer-term effects of the SFS on children's F\&V consumption.

\section{Acknowledgements}

Acknowledgements: The authors wish to thank the schools in NRW that served as study sites for the current analysis. Financial support: This work was funded by the MKULNV of NRW. The funder had no role in the design, analysis or writing of this article. Conflict of interest: All authors state that there are no conflicts of interest. Authorship: G.M. and M.H. designed the study, G.M. and especially S.M. conducted the data collection and developed the coding form. S.M. supervised and controlled the coding and conducted the statistical analyses, the latter with input from G.M. and M.H. S.M. wrote the first draft of the manuscript that was revised by M.H. All authors made substantive intellectual contributions to the scientific content and approved the final manuscript. Ethics of human subject participation: The study and data handling were approved by the Ministry of Education and the MKULNV of NRW as well as by the data protection officer of the University of Bonn. Anonymized number codes allowed to link baseline data to follow-up data for each individual.

\section{References}

1. Von Koerber K, Männle T, Leitzmann C et al. (2004) Gemüse und Obst. In Vollwert-Ernährung - Konzeption einer zeitgemäßen und nachbaltigen Ernäbrung, pp. 227-238 [K Koerber, T Männle and C Leitzmann, editors]. Stuttgart: Karl F. Haug Verlag. 
2. Caballero B (2001) School health and community nutrition early nutrition and risk of disease in the adult. Public Health Nutr 4, 1335-1336.

3. Law M (2000) Dietary fat and adult diseases and the implications for childhood nutrition: an epidemiologic approach. Am J Clin Nutr 72, 5 Suppl., 1291S-1296S.

4. Boeing H, Bechthold A, Bub A et al. (2012) Critical review: vegetables and fruit in the prevention of chronic diseases. Eur J Nutr 51, 637-663.

5. Buijsse B, Feskens EJM, Schulze MB et al. (2009) Fruit and vegetable intakes and subsequent changes in body weight in European populations: results from the project on Diet, Obesity, and Genes (DiOGenes). Am J Clin Nutr 90, 202-209.

6. Pomerleau J, Lock K \& McKee M (2005) The burden of cardiovascular disease and cancer attributable to low fruit and vegetable intake in the European Union: differences between old and new Member States. Public Health Nutr 9 , 575-583.

7. World Health Organization (2004) Fruit and Vegetables for Health - Report of a Joint FAO/WHO Workshop, 1-3 September 2004, Kobe, Japan. http://www.who.int/ dietphysicalactivity/publications/fruit_vegetables_report.pdf (accessed February 2013).

8. Currie C, Zanotti C, Morgan A et al. (2012) Social determinants of health and well-being among young people. Health Behaviour in School-aged Children (HBSC) study: international report from the 2009/2010 survey. http://www.euro. who.int/_data/assets/pdf_file/0007/167281/E96444_part1.pdf (accessed October 2013).

9. Yngve A, Wolf A, Poortyliet E et al. (2005) Fruit and vegetable intake in a sample of 11- year-old children in 9 European countries: the Pro Children Cross-Sectional Survey. Ann Nutr Metab 49, 236-245.

10. World Health Organization (2003) Diet, Nutrition and the Prevention of Chronic Diseases. Joint FAO/WHO Expert Consultation. WHO Technical Report Series no. 916. Geneva: WHO.

11. Mensink GBM, Heseker H, Richter A et al. (2007) Ernährungsstudie als KiGGS-Modul (EsKiMo). Bonn: Forschungsbericht im Auftrag des BMELV.

12. Alexy U, Clausen K \& Kersting M (2008) Die Ernährung gesunder Kinder und Jugendlicher nach dem Konzept der Optimierten Mischkost. Ernährungs-Umschau 3, 168-177.

13. Baranowski T, Davis M, Resnicow K et al. (2000) Gimme 5 fruit, juice and vegetables for fun and health: outcome evaluation. Health Educ Behav 27, 96.

14. Bere E, Veierød MB, Bjelland M et al. (2006) Outcome and process evaluation of a Norwegian school-randomized fruit and vegetable intervention: Fruits and Vegetables Make the Marks (FVMM). Health Educ Res 21, 258-267.

15. Glanz K \& Bishop DB (2010) The role of behavioral science theory in development and implementation of public health interventions. Annu Rev Public Health 31 , 399-418.

16. Bandura A (1986) Social Foundations of Thought and Action: A Social Cognitive Theory. Englewood Cliffs, NJ: Prentice-Hall.

17. Contento I, Balch GI, Bronner YL et al. (1995) Theoretical frameworks or models for nutrition education. J Nutr Educ 27, 287-290.

18. Bandura A (1997) Self-Efficacy - The Exercise of Control, 1st ed. New York: W.H. Freeman.

19. Bandura A (1998) Health promotion from the perspective of social cognitive theory. Psychol Health 13, 623-649.

20. World Health Organization (1986) Ottawa-Charta zur Gesundheitsförderung 1986. http://www.euro.who.int/_ data/assets/pdf_file/0006/129534/Ottawa_Charter_G.pdf (accessed June 2013).
21. Evans CEL, Christian MS \& Cleghorn CL (2012) Systematic review and meta-analysis of school-based interventions to improve daily fruit and vegetables intake in children 5 to $12 \mathrm{y}$. Am J Clin Nutr 96, 889-901.

22. Van Cauwenberghe E, Maes L, Spittaels H et al. (2009) Effectiveness of school-based interventions in Europe to promote healthy nutrition in children and adolescents: systematic review of published and 'grey' literature. $\mathrm{Br} J$ Nutr 103, 781-797.

23. De Sa J \& Lock K (2008) Will European agricultural policy for school fruit and vegetables improve public health? A review of school fruit and vegetable programmes. Eur J Public Health 18, 558-568.

24. Knai C, Pomerleau J, Lock K et al. (2006) Getting children to eat more fruit and vegetables: a systematic review. Prev Med 42, 85-95.

25. Heindl I \& Plinz-Wittorf C (2010) Schulische Ernährungsund Verbraucherbildung - Stand der curricularen Entwicklungen. In Haushalt und Bildung, pp. 4-11 [S Heindl, editor]. Baltmannsweiler: Schneider Verlag Hohengehren.

26. Pérez-Rodrigo C \& Aranceta J (2003) Nutrition education in schools: experiences and challenges. Eur J Clin Nutr 57, Suppl. 1, 82-85.

27. Pérez-Rodrigo C, Klepp K-I, Yngve A et al. (2001) The school setting: an opportunity for the implementation of dietary guidelines. Public Health Nutr 4, 717-724.

28. European Commission (2008) The EU's role - School Fruit Scheme: EU initiative - legal basis. http://ec.europa.eu/ agriculture/sfs/european-commission/legal-basis_en.htm (accessed June 2013).

29. Edmunds LD \& Ziebland S (2002) Development and validation of the Day in the Life Questionnaire (DILQ) as a measure of fruit and vegetable questionnaire for 7-9 year olds. Health Educ Res 17, 211-220.

30. Böhm A, Ellsäßer G \& Lüdecke K (2007) Der Brandenburger Sozialindex: ein Werkzeug für die Gesundheits- und Sozialberichterstattung auf Landes- und kommunaler Ebene bei der Analyse von Einschülerdaten. Gesundheitswesen 69 , $555-559$.

31. Rössler P (2010) Inhaltsanalyse, 2nd ed. Konstanz: UVK.

32. Holsti R (1969) Content Analysis for the Social Sciences and Humanities. Reading, MA: Addison-Wesley.

33. Raudenbush W \& Bryk AS (2002) Hierarchical Linear Models: Applications and Data Analysis Methods, 2nd ed. Thousand Oaks, CA: SAGE Publications, Inc.

34. Rasbash J, Steele F, Browne WJ et al. (2009) A User's Guide to MLwiN Version 2.10; Centre of Multilevel Modelling, University of Bristol. http://www.bristol.ac.uk/cmm/software/ mlwin/download/manual-print.pdf (accessed September 2012).

35. Healy MJR (2001) Multilevel data and their analysis. In Multilevel in Modelling Health Statistics, pp. 1-12 [AH Leyland and H Goldstein, editors]. Chichester: John Wiley \& Sons.

36. French SA \& Stables G (2003) Environmental interventions to promote vegetable and fruit consumption among youth in school settings. Prev Med 37, 593-610.

37. Edmunds L \& Jones C (2003) Evaluation of the Sustain Grab 5! school fruit and vegetable project - Evaluation Report May 2003. http://www.sustainweb.org/pdf/g5_eval. pdf (accessed September 2015).

38. Bere E, Veierød MB \& Klepp K-I (2005) The Norwegian School Fruit Programme: evaluating paid vs. no-cost subscriptions. Prev Med 41, 463-470.

39. Fogarty AW, Antoniak M, Venn AJ et al. (2007) Does participation in a population-based dietary intervention scheme have a lasting impact on fruit intake in young children? Int J Epidemiol 36, 1080-1085.

40. Bere E, te Velde SJ, Småstuen MC et al. (2015) One year of free school fruit in Norway -7 years of follow-up. Int $J$ Behav Nutr Phys Act 12, 139. 
41. Bere E, Brug J \& Klepp K-I (2008) Why do boys eat less fruit and vegetables than girls? Public Health Nutr 11, 321-325.

42. Rasmussen M, Krølner R, Klepp K-I et al. (2006) Determinants of fruit and vegetable consumption among children and adolescents: a review of the literature, Part I: quantitative studies. Int J Behav Nutr Phys Act 3, 22.

43. Cooke LJ \& Wardle J (2005) Age and gender differences in children's food preferences. Br J Nutr 93, 741-746.

44. Emanuel AS, McCully SN, Gallagher KM et al. (2012) Theory of Planned Behavior explains gender difference in fruit and vegetable consumption. Appetite 59, 693-697.
45. McKinley MC, Lowis C, Robson PJ et al. (2005) It's good to talk: children's views on food and nutrition. Eur J Clin Nutr 59, 542-551.

46. Eriksen K, Haraldsdóttir J, Pederson R et al. (2003) Effect of a fruit and vegetable subscription in Danish schools. Public Health Nutr 6, 57-63.

47. Methner S (2015) Intervention zur Förderung des Obst- und Gemüsekonsums bei Schülern - Prozess- und Ergebnisevaluation des EU-Schulobstprogramms in NordrheinWestfalen. PhD Thesis, Landwirtschaftliche Fakultät der Rheinischen Friedrich-Wilhelms-Universität Bonn. 